\title{
Effect of eradication of Helicobacter pylori on gastric juice ascorbic acid concentrations
}

\author{
G M Sobala, C J Schorah, S Shires, D A F Lynch, B Gallacher, M F Dixon, A T R Axon
}

\begin{abstract}
Ascorbic acid, the reduced form of vitamin C, may protect against gastric cancer and is secreted by the normal stomach. Secretion is impaired in Helicobacter pylori (H pylori) associated chronic gastritis. This study examined if eradication of $\boldsymbol{H}$ pylori improves gastric juice ascorbate values. Fasting gastric juice and plasma samples were collected at endoscopy from patients participating in trials of $\boldsymbol{H}$ pylori eradication for duodenal ulcer disease and intestinal metaplasia before and up to 15 months after attempted eradication. Ascorbic acid and total vitamin $\mathbf{C}$ concentrations were determined by high performance liquid chromatography. In 12 patients in whom $H$ pylori was successfully eradicated gastric juice ascorbate and total vitamin $C$ concentrations and the ratio of juice to plasma vitamin $\mathbf{C}$ rose after treatment. Analysis after treatment suggested that the rise was greatest in patients with high final plasma vitamin $\mathbf{C}$ concentrations, even though these did not change with treatment. By contrast, in 22 patients in whom $H$ pylori eradication was unsuccessful there were no significant changes in juice or plasma concentrations after treatment. It is concluded that successful eradication of $H$ pylori improves secretion of vitamin $C$ into gastric juice. It is speculated that this increases protection against gastric cancer.

(Gut 1993; 34: 1038-1041)
\end{abstract}

Ascorbic acid, the reduced form of vitamin C, is thought to protect against gastric cancer. ${ }^{1}$ This may be through its action in scavenging nitrite ${ }^{23}$ and thus preventing the formation of nitrite derived mutagens, or alternatively through its less specific anti-oxidant properties. There is evidence that ascorbic acid is secreted in high concentrations into the normal stomach. ${ }^{45}$ This secretion fails with the onset of Helicobacter pylori ( $\mathrm{H}$ pylori) acute gastritis ${ }^{6}$ and remains impaired in $H$ pylori associated chronic gastritis. ${ }^{457} \mathrm{H}$ pylori infection has been shown in prospective epidemiological studies to be a risk factor for gastric cancer. ${ }^{8-10}$ Can gastric juice ascorbic acid secretion be restored by eradication of $H$ pylori?

\section{Methods}

This hypothesis was tested by two ongoing trials of $H$ pylori eradication treatment, one in patients with duodenal ulcer (DU) disease and the other in patients with intestinal metaplasia (IM). The primary aim of the first trial was to discover if, after conventional healing of duodenal ulcers, eradication of $H$ pylori prevented ulcer relapse. The primary aim of the second trial was to see if eradication of $H$ pylori led to resolution of intestinal metaplasia.

\section{PATIENT RECRUITMENT}

The main selection criterion in the DU trial was a duodenal ulcer, freshly healed by standard acid suppressive treatment. All subjects gave fully informed written consent.

For the IM trial, subjects with intestinal metaplasia in previous gastric mucosal biopsies were identified from pathology department records and were asked to participate in the study. All gave fully informed written consent. They had another endoscopy and four antral and four body biopsy specimens were obtained for histological examination. Intestinal metaplasia in four or more biopsy specimens was the main criterion for inclusion in the study.

\section{TREATMENT}

Patients in the DU trial were randomised to receive one of two treatments for one week: either colloidal bismuth subcitrate (DeNol tab) $120 \mathrm{mg}$ four times daily alone, or in conjunction with ampicillin $500 \mathrm{mg}$ four times daily and metronidazole $400 \mathrm{mg}$ three times daily. Patients in the IM trial were randomised to receive two weeks of treatment with either placebo (lactose tablets) or a combination of colloidal bismuth subcitrate (DeNol tab) $120 \mathrm{mg}$ four times daily, oxytetracycline $500 \mathrm{mg}$ four times daily, and metronidazole $400 \mathrm{mg}$ three times daily.

FOLLOW UP

Both trial protocols required endoscopy to be performed before the start of treatment, and one, six and, 12 months after the end of treatment. In the DU trial an endoscopy was also performed on development of symptoms suggestive of ulcer relapse.

SPECIMEN COLLECTION AND ANALYSIS

At each endoscopy, biopsy specimens were taken for histological examination (DU trial: two antral, one body; IM trial: four antral, four body). An attempt was made where possible to aspirate gastric juice using a Teflon catheter passed down the suction biopsy channel. Collection was not always successful and thus samples were not obtained from all subjects at all stages of the trials. Gastric juice was stored at $-70^{\circ} \mathrm{C}$ in an equal volume of $2 \%$ metaphosphoric $/ 0.5 \%$ sulphamic acid until analysis. ${ }^{7}$ Blood was drawn 


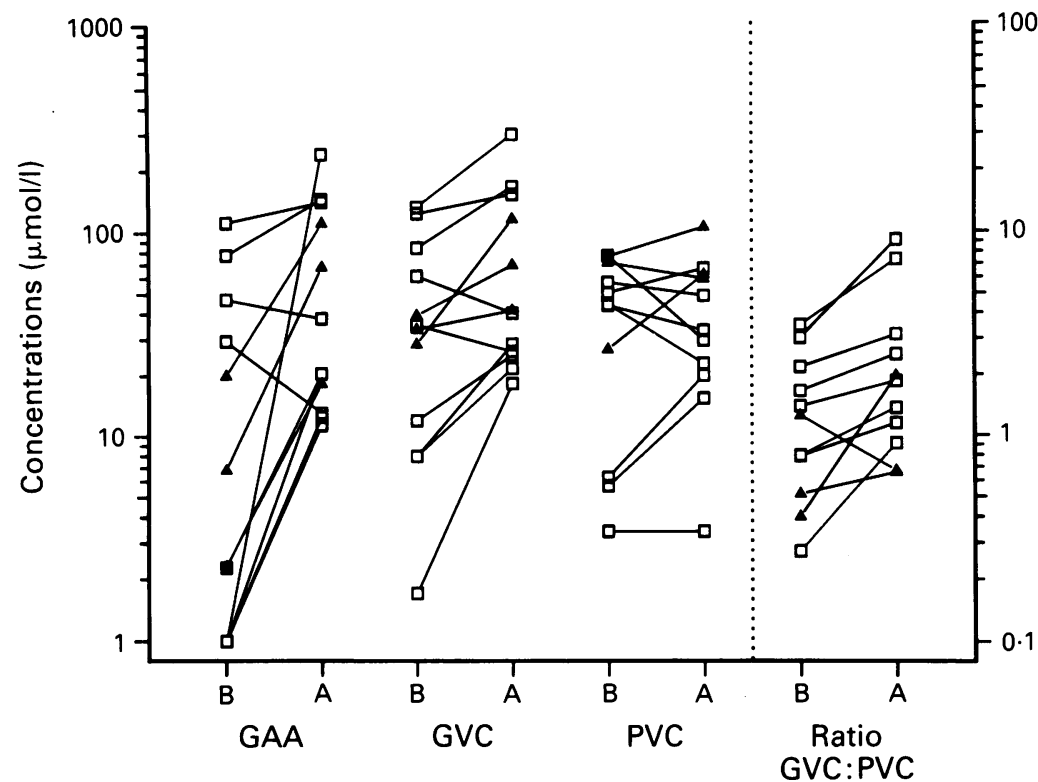

Figure 1: Patients in whom $\mathrm{H}$ pylori was successfully eradicated $(B)$ before and $(A)$ after treatment. (GAA = gastric juice ascorbic acid; $G V C=$ gastric juice total vitamin $C ; P V C=$ plasma total vitamin $C ;$ Ratio GVC:PVC=ratio of juice to plasma total vitamin $C ; \square=D U$ trial patient; $\mathbf{\Delta}=I M$ trial patient. Concentrations $<1$ umol/l are shown as 1 umol/l.)

into a heparinised container for vitamin $\mathrm{C}$ assay and plasma was stored at $-70^{\circ} \mathrm{C}$ in two volumes of $2 \%$ metaphosphoric acid. ${ }^{7}$

Gastric juice and plasma ascorbic acid concentrations were determined by high performance liquid chromatography using acetonitrile mobile phase and an electrochemical detector. Total vitamin $\mathrm{C}$ concentrations were determined by a modification of our original technique ${ }^{7}$ after reduction of dehydroascorbic acid to ascorbic acid at $45^{\circ} \mathrm{C}$ for 120 minutes in the presence of excess dithiothreitol.

Gastric biopsy specimens were assessed by a single histologist (Dr M F Dixon) according to the Sydney classification system. ${ }^{11} H$ pylori was stained for by the modified Giemsa method. Eradication of $H$ pylori was defined as negative results by histological tests in all biopsy speci-

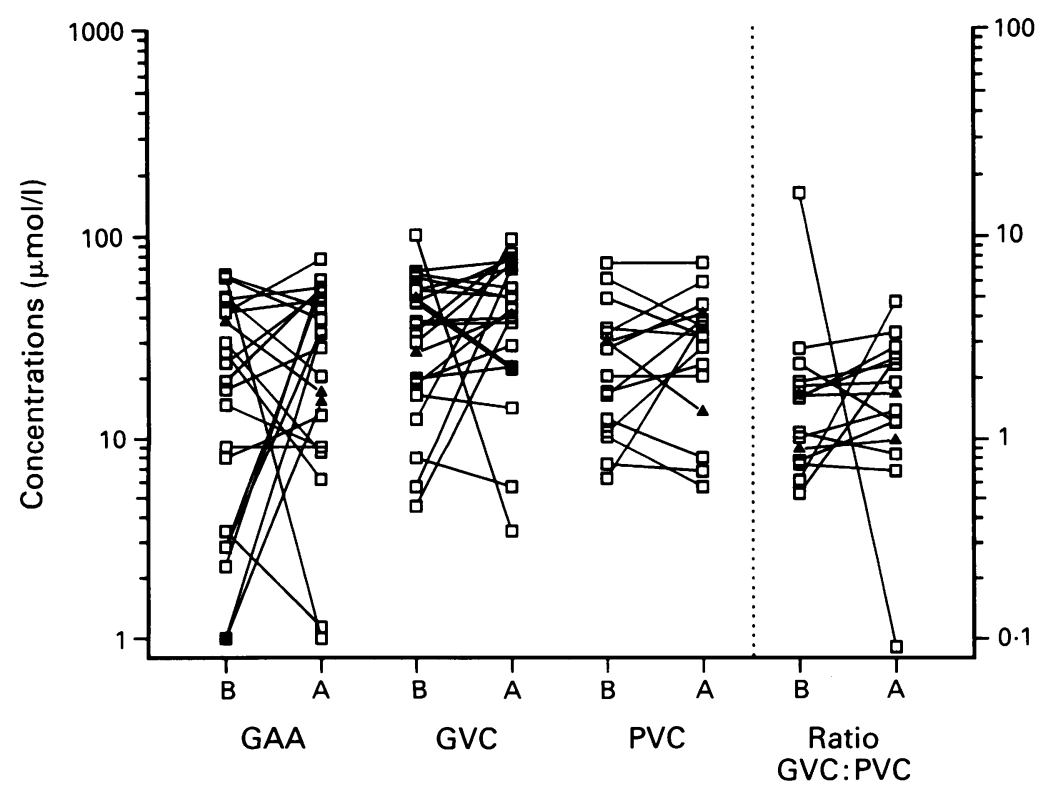

Figure 2: Patients in whom eradication of $\mathrm{H}$ pylori failed $(B)$ before and $(A)$ after treatment. Abbreviations and symbols as in Figure 1 . Concentrations $<1$ umol/l are shown as $1 \mu \mathrm{mol} / \mathrm{l}$. mens at least four weeks after the end of treatment.

STATISTICAL ANALYSIS

The juice vitamin concentration data showed skewing and therefore analyses were performed using non-parametric methods.

Subjects were divided into one of two groups according to whether $H$ pylori eradication was successful or not. Subjects in whom only before or after treatment values were available were excluded from the main analysis. Where subjects had several after treatment values available the latest was chosen for analysis on the grounds that this would best reflect the longterm effect of eradication.

Statistics were performed using Minitab v8.21 (Minitab Inc, Pennsylvania, USA). For each subgroup a Wilcoxon signed rank test was used to compare before and after treatment concentrations of gastric juice ascorbic acid and total vitamin $C$, plasma total vitamin $C$, and the ratio of gastric juice to plasma vitamin $\mathrm{C}$. The estimated median within subject before to after treatment differences and their approximate 95\% confidence intervals were calculated using Minitab procedure WINT. Unpaired analyses between groups were performed using a MannWhitney rank test. Quoted $p$ values are two tailed and an $\alpha$ level of 0.05 was considered significant.

\section{Results}

Altogether 131 juice and 119 plasma samples were obtained from 58 patients in the DU trials and 11 patients in the IM trial. There were no significant differences in before treatment juice or plasma results between patients drawn from the two trials and so the two datasets were combined to increase the power of the study.

Paired before and after treatment juice values were available for only 34 subjects (12 with successful $H$ pylori eradication, of whom nine were from the DU trial; 22 with failed $H$ pylori eradication, 20 from the DU trial). In some of these subjects plasma values were not available. Fewer than expected samples were obtained from patients with successful $H$ pylori eradication as the eradication rate with triple treatment in the DU trial was low at an overall $50 \% .^{12}$

There were no significant differences between before treatment gastric juice ascorbate or total vitamin $\mathrm{C}$ concentrations, or plasma total vitamin $\mathrm{C}$ concentrations between the two subgroups. The median times between start of treatment and the final follow up examination did not differ between the two subgroups: 63 days (range 35-224) in the successful eradication group, 118 days (range 35-454) in the failed eradication group ( $2 \mathrm{p}>0.50$; Mann-Whitney rank test).

Figures 1 and 2 show the effects of treatment on vitamin $\mathrm{C}$ concentrations in the two subgroups and they are summarised in Table I.

Gastric juice ascorbic acid and total vitamin $\mathrm{C}$ concentrations, and the ratio of gastric juice to plasma total vitamin $\mathrm{C}$ rose significantly after treatment only in the group in whom $H$ pylori 
TABLE I Median pre-treatment values, estimated median differences, and their approximate $95 \%$ confidence intervals for before $\mathrm{v}$ after treatment gastric juice ascorbic acid and total vitamin $C$ concentrations, plasma total vitamin $C$ concentration, and the ratio of gastric juice to plasma total vitamin $C$ in patients (a) in whom $\mathrm{H}$ pylori was successfully eradicated and $(b)$ in whom $\mathbf{H}$ pylori eradication failed

\begin{tabular}{|c|c|c|c|c|}
\hline Group & $\begin{array}{l}\text { Juice } \\
\text { ascorbic acid } \\
(\mu \mathrm{mol} / \mathrm{l})\end{array}$ & $\begin{array}{l}\text { Fuice total } \\
\text { vitamin } C \\
\text { ( } \mu \text { molll })\end{array}$ & $\begin{array}{l}\text { Plasma total } \\
\text { vitamin } C \\
(\mu \text { molll })\end{array}$ & $\begin{array}{l}\text { Ratio gastric to } \\
\text { plasma } \\
\text { vitamin } C\end{array}$ \\
\hline \multirow{2}{*}{$\begin{array}{l}\text { Successful eradication } \\
\text { No } \\
\text { Median pre-treatment } \\
\text { Estimated median difference } \\
\text { Approximate } 95 \% \text { confidence interval } \\
2 \mathrm{p} \\
\text { Failed eradication } \\
\text { No } \\
\text { Median pre-treatment } \\
\text { Estimated median difference } \\
\text { Approximate } 95 \% \text { confidence interval } \\
\text { p Values }\end{array}$} & $\begin{array}{c}12 \\
5 \\
+30 \\
+10,+76 \\
0 \cdot 011\end{array}$ & $\begin{array}{c}12 \\
34 \\
+23 \\
+6,+73 \\
0.021\end{array}$ & $\begin{array}{c}11 \\
44 \\
+1 \\
-16,+16 \\
0 \cdot 84\end{array}$ & $\begin{array}{l}11 \\
1 \cdot 25 \\
+0 \cdot 78 \\
+0 \cdot 29,+3 \cdot 10 \\
0.014\end{array}$ \\
\hline & $\begin{array}{l}22 \\
22 \\
+6 \\
-8,+19 \\
0 \cdot 37\end{array}$ & $\begin{array}{c}22 \\
36 \\
+9 \\
-3,+24 \\
0 \cdot 15\end{array}$ & $\begin{array}{c}16 \\
24 \\
+3 \\
-5,+13 \\
0 \cdot 43\end{array}$ & $\begin{array}{l}16 \\
1.34 \\
+0.31 \\
-0.11,+0.89 \\
0.09\end{array}$ \\
\hline
\end{tabular}

$\mathrm{p}$ Values are for test of significance of median difference by signed rank test and are two tailed.

TABLE II Changes in gastric juice ascorbic acid and total vitamin $C$ concentrations in the two subgroups according to final plasma vitamin $C(P V C)$ concentrations

\begin{tabular}{|c|c|c|}
\hline & $\begin{array}{l}\text { Final } P V C<30 \text { umolll) } \\
\text { median, range }(\mu \mathrm{mol} / \mathrm{l})\end{array}$ & $\begin{array}{l}\text { Final } P V C \geq 30 \mu \mathrm{mol} / \mathrm{l} \\
\text { median, range }(\mu \mathrm{mol} / \mathrm{l})\end{array}$ \\
\hline $\begin{array}{l}\text { Successful eradication } \\
\text { Change in juice ascorbate } \\
\text { Change in juice total vitamin } C \\
\text { Failed eradication } \\
\text { Change in juice ascorbate } \\
\text { Change in juice total vitamin C }\end{array}$ & $\begin{array}{l}n=5 \\
+13-16,+20 \\
+13-21,+20 \\
n=7 \\
+5-21,+59 \\
+3-27,+84\end{array}$ & $\begin{aligned} & n=6 \\
+65 & +16,+241 \\
+57 & +8,+167 \\
n=9 & \\
-19 & -65,36 \\
+2 & -98,+48\end{aligned}$ \\
\hline
\end{tabular}

was successfully eradicated. The changes in gastric juice ascorbic acid in the $H$ pylori eradicated group were significantly greater than in the non-eradicated group $(2 \mathrm{p}=0.038$; MannWhitney). The changes in gastric total vitamin $\mathrm{C}$ and the juice:plasma ratio were also higher in the $H$ pylori eradicated group but did not reach statistical significance $(2 \mathrm{p}=0.14$ and 0.11 respectively; Mann-Whitney).

Plasma vitamin C concentrations did not change significantly with treatment in either group.

The results of gastric juice against plasma concentrations according to $H$ pylori state are shown in Figure 3. This includes the unpaired

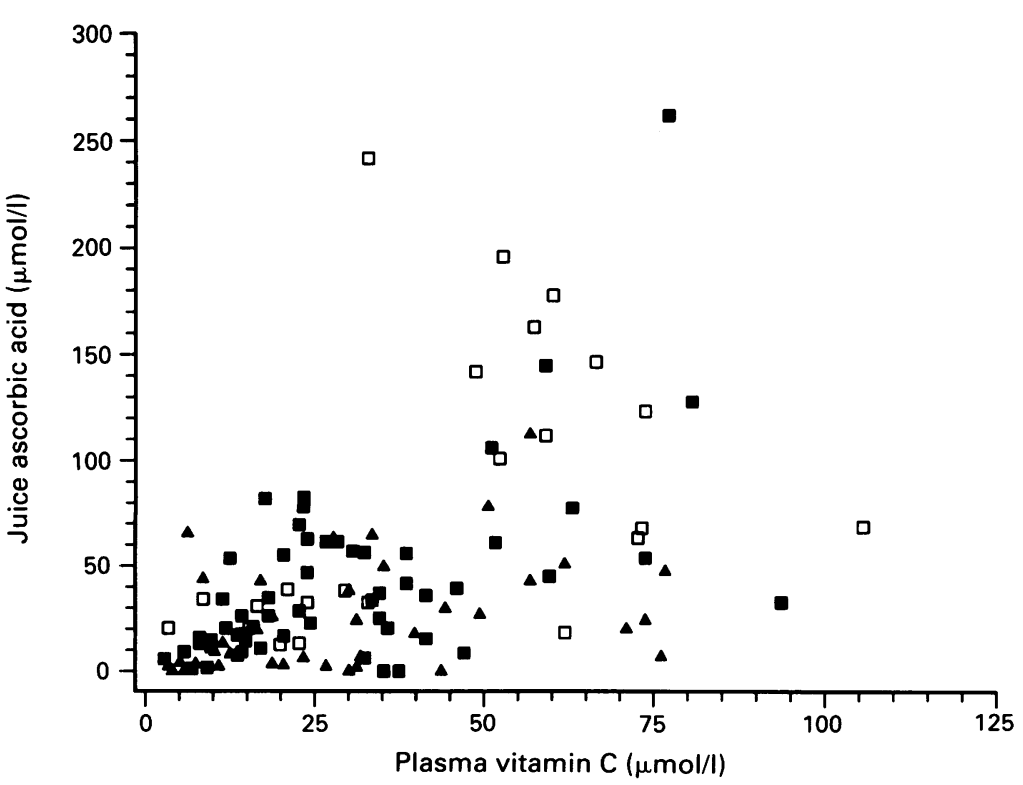

Figure 3: Gastric juice ascorbic acid concentration according to plasma vitamin $C$

concentrations in subjects $(a)$ before treatment, $(b)$ after successful $\mathrm{H}$ pylori eradication, and $(c)$ after unsuccessful $\mathbf{H}$ pylori eradication. $(\boldsymbol{\Delta}=$ Pre-treatment; $\square=$ successful $\mathbf{H}$ pylor eradication; $\mathbf{\square}=$ failed $\mathbf{H}$ pylori eradication $)$ datapoints and the repeated post-treatment datapoints which were excluded from the above pairwise analyses. This indicates that broadly similar juice ascorbate concentrations were found in $H$ pylori positive and negative subjects when plasma vitamin $\mathrm{C}$ concentrations were below about $30 \mu \mathrm{mol} / \mathrm{l}$, but above this threshold $H$ pylori eradicated patients tended to have higher juice concentrations. Table II shows this further by the changes in juice concentrations that occurred in the two subgroups according to whether the final plasma vitamin $\mathrm{C}$ concentration was high or low. The before to after treatment changes in gastric juice ascorbic acid $(2 p=0.023$; Mann-Whitney rank test $)$ and total vitamin $\mathrm{C}(2 \mathrm{p}=0.036)$ were significantly larger in the $H$ pylori eradicated patients with higher plasma concentrations than in those with lower concentrations. In patients in whom $H$ pylori eradication failed, changes in juice vitamin concentrations did not differ significantly according to the final plasma value.

One patient (man aged 69) in whom $H$ pylori had successfully been eradicated was recalled for further study. On recall, fasting gastric juice ascorbate concentration was only $4 \mu \mathrm{mol} / \mathrm{l}$ and plasma vitamin $\mathrm{C}$ was $5 \mu \mathrm{mol} / \mathrm{l}$. Sixty minutes after $500 \mathrm{mg}$ of ascorbate was given intravenously, however, gastric juice ascorbate concentration had risen to $248 \mu \mathrm{mol} / \mathrm{l}$. After one week of ascorbic acid ( $1 \mathrm{~g}$ orally daily) his fasting gastric juice ascorbate was $692 \mu \mathrm{mol} / \mathrm{l}$ (36 hours after last oral vitamin dose), plasma vitamin C having risen to $128 \mu \mathrm{mol} / \mathrm{l}$.

\section{Discussion}

In this study, gastric juice concentrations of ascorbic acid and total vitamin $\mathrm{C}$, and the concentration gradient between plasma and gastric juice were improved by eradication of $H$ pylori. As eradication of $H$ pylori is known to restore chronic gastritis to normal,,$^{13}$ this is in agreement with findings of low juice ascorbate concentrations in $H$ pylori chronic gastritis and high concentrations in patients with normal gastric mucosa. ${ }^{457}$

The effect of eradication in this study was variable, however, as some patients exhibited appreciable rises in juice vitamin concentrations whereas others showed little change. It is likely that this variability was related to the individual's ascorbic acid state (Table II). Patients who were comparatively deficient in vitamin $\mathrm{C}$ with plasma concentrations below about $30 \mu \mathrm{mol} / \mathrm{l}$ did not secrete much ascorbate into gastric juice even after $H$ pylori eradication. High increments in gastric juice ascorbate concentrations only occurred if the subjects had final plasma vitamin $\mathrm{C}$ concentrations above approximately $30 \mu \mathrm{mol} / 1$. This is a retrospective analysis and so should be interpreted with caution, but our study of one patient with vitamin C deficiency and with $H$ pylori eradicated does lend some supporting evidence.

$H$ pylori infection is now recognised as a major independent risk factor in the cause of gastric cancer. ${ }^{8-10}$ Reduction of gastric ascorbate secretion may be one mechanism by which it increases the risk. An attempt could be made to reverse 
this by increasing the dietary intake of vitamin C, but we have shown in a region of Venezuela with a high incidence of gastric cancer that oral vitamin $\mathrm{C}$ supplementation alone is insufficient to increase gastric juice ascorbate concentrations in the presence of $H$ pylori infection. ${ }^{14} \mathrm{We}$ conclude from this study that $H$ pylori eradication enhances gastric juice ascorbate secretion, and thus increases intragastric anti-oxidant protection. Further work is underway to confirm whether dietary vitamin $\mathrm{C}$ supplementation enhances this effect, and to discover if such an approach can reverse precancerous conditions in the gastric mucosa.

This study was supported by a grant from the Special Trustees of Leeds General Infirmary.

1 Chen LH, Boissoneault GA, Glauert HP. Vitamin C, vitamin E and cancer. Anticancer Res 1988; 8: 739-48.

2 Mirvish SS, Wallcave L, Eagan M, Shubik P. Ascorbatenitrite reaction: possible means of blocking the formation of carcinogenic N-nitroso compounds. Science 1972; 177 65-8.

3 Bartsch H, Ohshima H, Pignateli B. Inhibitors of endogenous nitrosation. Mechanisms and implications in human cancer prevention. Mutat Res 1988; 202: 307-24.

4 Sobala GM, Schorah CJ, Sanderson M, Dixon MF, Tompkins DS, Godwin P, et al. Ascorbic acid in the human stomach. Gastroenterology 1989; 97: 357-63.

5 Rathbone BJ, Johnson AW, Wyatt JI, Kelleher J, Heatley RV,
Losowsky MS. Ascorbic acid: a factor concentrated in human gastric juice. Clin Sci 1989; 76: 237-41.

6 Sobala GM, Crabtree JE, Dixon MF, Schorah CJ, Taylor JD, Rathbone BJ, et al. Acute Helicobacter pylori infection: clinical features, local and systemic immune response gastric mucosal histology and gastric juice ascorbic acid concentrations. Gut 1991; 32: 1415-8.

7 Sobala GM, Pignatelli B, Schorah CJ, Bartsch H, Sanderson $M$, Dixon MF, et al Simultaneous determination of ascorbic acid nitrite, total nitrosocompounds and bile acids in fasting gastric juice, and gastric mucosal histond gastric juice, and gastric mucosal histology: implication

8 Forman D, Newell DG, Fullerton F, Yarnell JWG, Stacey AR, Wald N, et al. Association between infection with AR, Wald N, et al. Association between infection with Helicobacter pylori and risk of gastric cancer: evidence

9 Parsonnet J, Friedman GD, Vandersteen DP, Change Y Vogelman $\mathrm{JH}$, Orentreich $\mathrm{N}$, et al. Helicobacter pylor infection and the risk of gastric carcinoma. $N \mathrm{Engl} f \mathrm{Med}$ 1991; 325: 1127-31.

10 Nomura A, Stemmermann GN, Chyou P-H, Kato I, PerezPerez GI, Blaser MJ. Helicobacter pylori infection and gastric carcinoma among Japanese Americans in Hawaii. N Englf Med 1991; 325: 1132-6.

11 Price AB. The Sydney System: a new classification of gastritis Histological division. $\mathcal{F}$ Hepatol Gastroenterol 1991; 6: 209-22.

12 Sobala GM, Lynch DAF, Gallacher B, Dixon MF, Axon ATR. Eradication of $H$ pyrlori prevents duodenal ulcer recurrence. Ir F Med Sci 1992; 161 (suppl 10): 89 .

13 Rauws EAJ, Langenberg W, Houthoff $\mathrm{HJ}$, Zanen $\mathrm{HC}$, Tytga GNJ. Campylobacter pyloridis associated chronic antra gastritis. A prospective study of its prevalence and the effects of antibacterial and antiulcer treatment. Gastroenterolog 1988; 94: 33-40.

14 Munoz N, Oliver W, Sobala GM, de Sanjose S, Cano E, Peraza $\mathrm{S}$, et al. Prevalence of Helicobacter pylori infection and effect of anti-oxidants in a high-risk population for gastric cancer in Venezuela. Ital f Gastroenterol 1991; 23 (suppl 2): 